ORIGINAL ARTICLE

\title{
Elevated plasma lactate level associated with high dose inhaled albuterol therapy in acute severe asthma
}

\author{
G J Rodrigo, C Rodrigo
}

Emerg Med J 2005;22:404-408. doi: 10.1136/emj.2003.012039

See end of article for authors' affiliations .....................

Correspondence to: G J Rodrigo, MD, Departamento de Emergencia, Hospital Central de las Fuerzas Armadas, Av. 8 de Octubre 3020, Montevideo 11600 Uruguay; gurodrig@ adinet.com.uy

Accepted for publication 19 January 2004

\begin{abstract}
Background: Lactic acidosis is a recognised event in adult patients with status asthmaticus, particularly in the setting of intensive care. However, it has been infrequently studied in patients attending the emergency departments (ED).

Methods: We conducted a prospective and descriptive study to assess levels of lactate and effects on bronchodilator response in adult patients with acute severe asthma treated with high doses of albuterol in the ED. In total, 18 subjects (mean (SD) age 42.9 (2.7) years, $\mathrm{FEV}_{1}=32.2$ (10.9)\% of predicted) who presented to an emergency department were enrolled in the study. All patients were treated with albuterol; four puffs (100 $\mu \mathrm{g} /$ puff) at 10 minute intervals, delivered by a pressurised metered dose inhaler into a spacer device over a 2 hour period.

Results: At the end of treatment, mean (SD) plasma lactate level $(2.94(2.1) \mathrm{mmol} / \mathrm{l})$ was significantly higher $(p=0.001)$ than baseline. Of the 18 patients, nine $(50 \%)$ showed lactate levels $\geqslant 2.5 \mathrm{mmol} / \mathrm{l}$ (four patients presented values $>4 \mathrm{mmol} / \mathrm{l})$; these patients had a shorter duration of attack prior to $E D$ presentation $(p=0.01)$, a higher pretreatment heart rate $(p=0.005)$, a lower pretreatment $\mathrm{SpO}_{2}$ $(p=0.03)$, a lower pretreatment $\mathrm{PO}_{2}(p=0.009)$, a higher pretreatment $\mathrm{PCO}_{2}$, and a lower pretreatment serum potassium $(p=0.005)$. However, there were no significant differences in the airway response between groups.

Conclusions: This study confirmed previous observations that high lactate concentrations can develop during the first hours of inhaled beta agonist treatment. The presence of a previous hyperadrenergic state may predispose to the development of this condition. A significant improvement in lung function was associated with elevated lactate levels.
\end{abstract}

actic acidosis is a recognised event in adult patients with acute severe asthma, particularly in an intensive care - setting. ${ }^{1-4}$ A prevalence of $16-40 \%$ has been reported. ${ }^{23}$ However, the condition has been infrequently studied in patients attending the emergency department (ED). It has been postulated that a sharp increase in lactate concentrations (hyperlactataemia) could be due to the administration of large doses of intravenous or inhaled $\beta_{2}$ agonists, and perhaps also to endogenous catecholamine levels related to marked respiratory distress. ${ }^{56}$ Lactic acidosis has been reported in cases of $\beta_{2}$ adrenergic agonist therapy for tocolysis in premature labour ${ }^{7}$ and in acute asthma. ${ }^{6-12}$ It is probable that the pathogenesis involves a combination of factors, but the reason why only a proportion of patients with asthma treated with beta agonists develops lactic acidosis remains to be clarified. There are several reasons to carry out measurement of lactate in acute asthma patients: $(a)$ it has been suggested that lactic acidosis is an indicator of the severity of an asthma attack and a precursor of respiratory failure; ${ }^{2}{ }^{4}(b)$ high lactate levels may produce sufficient acidosis to inhibit the bronchodilatation in response to exogenous beta agonists and to endogenous catecholamines, ${ }^{13}$ and to generate disturbances that can lead to serious adverse effects on the cardiovascular system; and (c) the increased respiratory effort related to acidosis stimulation of ventilation can encourage more aggressive and inappropriate therapy. The aim of this prospective and descriptive study was to assess levels of lactate and the effects on bronchodilator response in adult patients with acute severe asthma treated with high doses of albuterol in the ED.

\section{METHODS}

\section{Subjects}

We studied all adult patients with acute asthma who were seen in the ED of the Hospital Central de las Fuerzas Armadas in Montevideo, Uruguay, over a 3 month period (March-May 2003). The inclusion criteria for patients were: $(a)$ diagnosis of asthma based on the criteria of of the Global Initiative for Asthma, ${ }^{14}(b)$ age between 18 and 50 years and $(c)$ a forced expiratory volume in 1 second $\left(\mathrm{FEV}_{1}\right)<50 \%$ of predicted value. Patients were excluded if they had: $(a)$ a temperature $>38^{\circ} \mathrm{C}$ or $(b)$ a history of cardiac, hepatic, renal, or other disease, or were pregnant. Patients who expressed willingness to participate in the study gave their written informed consent, and the hospital ethics committee approved the study.

\section{Protocol}

After initial assessment, all patients were treated with albuterol, four puffs for each dose, delivered at 10 minute intervals by a pressurised metered dose inhaler into a spacer device (Volumatic; Allen \& Hansburys Ltd, UK). As each puff $(100 \mu \mathrm{g})$ was delivered into the spacer, the patient performed a deep inhalation from the spacer. The protocol involved 120 minutes of this treatment $(1200 \mu \mathrm{g}$ of albuterol every 30 minutes). After this time, all patients with a poor response $\left(\mathrm{FEV}_{1}<50 \%\right.$ of predicted) received intravenous hydrocortisone $500 \mathrm{mg}$. The protocol included the administration of $\mathrm{O}_{2}$

Abbreviations: ED, emergency department 
if arterial oxygen saturation measured by pulse oximetry $\left(\mathrm{SpO}_{2}\right)$ decreased to $<92 \%$. Other medications were excluded in all patients. Patients were discharged from the ED according to all following criteria: if accessory muscle use and dyspoea had abated, if wheezing was judged as minimal to completely resolved, and if $\mathrm{FEV}_{1}$ was $>60 \%$ of predicted. The physicians prescribed oral prednisone (60 mg for 7 days) for all discharged patients, or intravenous steroids for those who were admitted.

\section{Measurements}

The following variables were measured in each patient immediately before starting treatment and at 30 minute intervals until 2 hours after presentation: $\mathrm{FEV}_{1}$, respiratory rate, heart rate, accessory muscle use, dyspnoea, wheezing, and $\mathrm{SpO}_{2}$. Additionally, $\mathrm{pH}, \mathrm{PaO}_{2}, \mathrm{PaCO}_{2}, \mathrm{HCO}_{3}, \mathrm{~K}, \mathrm{Na}, \mathrm{Cl}$, and lactate levels, and arterial mean pressure were obtained at baseline and at the end of protocol. $\mathrm{FEV}_{1}$ was measured using a Vitalograph Compact spirometer (Vitalograph Ltd., Maids Moreton House, Buckingham, UK). Three successive maximal expiratory curves were recorded at each assessment, and the highest value was selected, according to the criteria of the American Thoracic Society. ${ }^{15}$ Heart rate was measured from continuous electrocardiogram. Arterial oxygen saturation was monitored by pulse oximetry with a finger oximeter (Nellcor N-180 Pulse oximeter; Hayward, CA, USA). Accessory muscle use was defined as visible retraction of the sternocleidomastoid muscles. ${ }^{16}$ Dyspnoea was defined as the patient's own assessment of breathlessness. $\mathrm{PaO}_{2}, \mathrm{PaCO}_{2}$, and $\mathrm{pH}$ were measured with a blood gas analyser using routine techniques (ABL 500 system; Radiometer America Westlake, OH, USA). Plasma $\mathrm{Na}, \mathrm{K}$, and $\mathrm{Cl}$ were assayed by flame photometry (Radiometer EMI 100). Finally, arterial lactate concentrations (normal value $\leqslant 2.2 \mathrm{mmol} / \mathrm{l}$ ) were performed using a blood gas analyser (Rapid lab 864; Chiron Diagnostics, Bayer; Leverkusen, Germany). To determine duration of onset of present attack, patients were asked to indicate the onset of wheeze, cough, shortness of breath, or some combination of these symptoms, and additionally, any decline in peak flow, if available, was noted.

\section{Statistical analysis}

Means (SD) were calculated for continuous variables. The 95\% confidence intervals (CI) were obtained with standard formulas. ${ }^{17}$ Changes in $\mathrm{FEV}_{1}$ were evaluated using repeated measures analysis of variance. When the $F$ value indicated significant differences among group means, post hoc pairwise multiple comparisons were performed using the Newman-Keuls test. Baseline and final data were compared by the Mann-Whitney $U$ test for independent samples, or Wilcoxon matched pairs signed rank test for related samples. The $\chi^{2}$ test with Yates' correction or Fisher's exact test was used for categorical variables. All data were analysed with the SPSS for Window software package (version 11.0; SPSS Inc., Chicago, IL, USA). A p value $<0.05$ using a two tailed test was taken as significant for all statistical tests.

\section{RESULTS}

In total, 20 consecutive adults with an acute exacerbation of asthma were recruited for entry into this study. Two patients were excluded because they were unable to perform spirometry, thus 18 adults completed the study (mean age 42.9 (2.7) years). Baseline characteristics of patients are presented in table 1 . They had severe airway obstruction (mean $\mathrm{FEV}_{1} 32.2$ (10.9)\% of predicted), moderate hypoxaemia (mean $\mathrm{PaO}_{2} 76.6$ (11.7) $\mathrm{mmHg}$ ), hypocarbia (mean $\mathrm{PaCO}_{2} 35.9$ (3.3) mmHg), and normal pH (7.41 (0.02). No

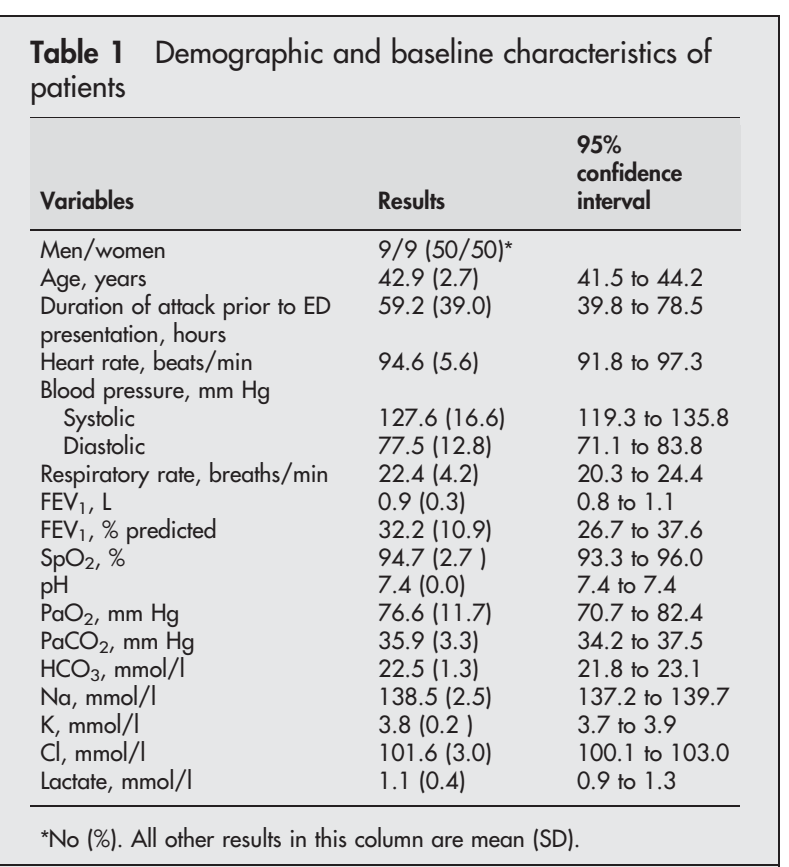

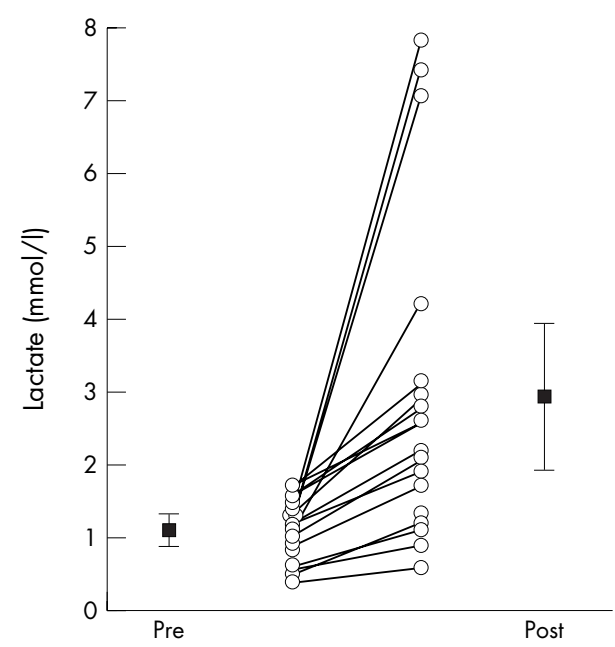

Figure 1 Baseline and postreatment lactate levels. Circles represent individual values and squares mean (SD) values. The mean serum lactate level at the end of treatment was significantly higher $(p=0.001)$ than baseline.

intubated or ventilated patients were included in the study. Although all patients had received beta agonists 24 hours before their arrival in the ED, plasma lactate levels were within normal values $(<2.2 \mathrm{mmol} / \mathrm{l})$ in all patients.

The relationship between cumulative doses of albuterol and change in $\mathrm{FEV}_{1}$, heart rate, and $\mathrm{SpO}_{2}$ were analysed. Overall, patients demonstrated improved lung function and gas exchange, and showed an increase in heart rate as a response to $\beta_{2}$ agonist treatment. There were dose related significant increases in the three variables over baseline values $(\mathrm{p}<0.001)$. At final disposition, the mean values of $\mathrm{FEV}_{1}$, heart rate, and $\mathrm{SpO}_{2}$ were $71.3(22.2) \%, 101.6$ (8.2) beats/min, and 97.4 (1.5)\% respectively.

At the end of treatment, the mean plasma lactate level (2.94 (2.1) $\mathrm{mmol} / \mathrm{l})$ was significantly higher $(\mathrm{p}=0.001)$ than 


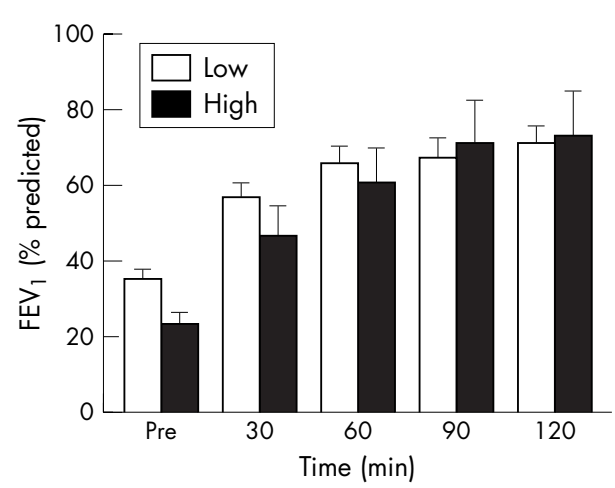

Figure $2 \mathrm{FEV}_{1}$ values (\% of predicted) in patients with final low $(<4.0 \mathrm{mmol} / \mathrm{l})$ and high ( $\geqslant 4.0 \mathrm{mmol} / \mathrm{l})$ lactate levels after the administration of high doses of albuterol. Data points are mean values, and the brackets represent 1 SD. There were no significant differences between both subgroups.

baseline (fig 1). After 2 hours of treatment, nine patients $(50 \%$ ) showed lactate levels $\geqslant 2.5 \mathrm{mmol} / \mathrm{l}$ (four patients presented values $>4 \mathrm{mmol} / \mathrm{l}$ ). Final lactate concentration was significantly correlated with pretreatment heart rate $(\rho=0.58,95 \%$ CI 0.15 to $0.82, p=0.01)$ and inversely correlated with baseline serum potassium $(\rho=-0.48,95 \%$ CI -0.78 to $-0.09, \mathrm{p}=0.04)$. When patients were classified according to final lactate concentration (patients with low lactate concentrations $(<4 \mathrm{mmol} / \mathrm{l})$ versus patients with very high lactate concentrations $(\geqslant 4 \mathrm{mmol} / \mathrm{l}))$, significant relationships were found. Patients with final high lactate concentrations had a shorter duration of attack prior to ED presentation (three patients presented a duration of attack $<3$ hours; $\mathrm{p}=0.01)$, a higher pretreatment heart rate $(\mathrm{p}=0.005)$, a lower pretreatment $\mathrm{SpO}_{2}(\mathrm{p}=0.03)$, a lower pretreatment $\mathrm{PO}_{2}(\mathrm{p}=0.009)$, a higher pretreatment $\mathrm{PCO}_{2}$, and a lower pretreatment serum potassium $(p=0.005)$. In addition, there was a non-significant lower pretreatment pulmonary function $\left(\mathrm{FEV}_{1}\right)$. In contrast, there were no differences between the two subgroups in baseline lactate level (table 2). $\mathrm{FEV}_{1}$ responses at each time point during treatment for the two subgroups are shown in fig 2. There were no significant differences in the airway response. At final disposition (120 minutes), the mean percentage predicted $\mathrm{FEV}_{\mathrm{I}}$ was $70.9(23.0) \%$ in the low lactate level subgroup, and $73.0(22.6) \%$, in the high lactate level subgroup (mean difference -2.1 , 95\% CI -29.6 to 25.4 , $\mathrm{p}=0.7)$.

\section{DISCUSSION}

Although lactic acidosis is a common metabolic disturbance in acute asthma, its pathogenesis remains controversial. In type A lactic acidosis, the impaired oxygen delivery or consumption leads to increased anaerobic glycolysis with terminal conversion of the resulting pyruvate to lactate instead of through the Krebs cycle of aerobic metabolism. Thus, in sepsis and shock, lactic acidosis is used as a marker of disease severity. ${ }^{18}{ }^{19}$ On the other hand, type B lactic acidosis is associated with an altered cellular metabolism (in absence of hypoperfusion or hypoxia), with either decreased lactate metabolism or increased flux of pyruvate to lactate rather than into the Krebs cycle. ${ }^{20}$ Conditions associated with type B lactic acidosis include inborn errors of metabolism (pyruvate dehydrogenase deficiency), systemic disorders (liver failure), and adverse effects of medications (ethanol, metformin, and corticoids). ${ }^{10}$ It has also been postulated that endogenous (distress) or exogenous (drugs) adrenergic stimulation may be associated with increased conversion of pyruvate to lactate. ${ }^{6}$ Stimulation of $\beta$-adrenergic receptors leads to a variety of metabolic effects, including increases in fatty acids and plasma glucose concentrations, ${ }^{21}$ glycogenolysis,

\begin{tabular}{|c|c|c|c|c|}
\hline Variable & Low $(n=14)$ & High $(n=4)$ & $\mathbf{p}$ & $\begin{array}{l}\text { Mean difference } \\
(95 \% \mathrm{Cl})\end{array}$ \\
\hline \multicolumn{5}{|l|}{ Baseline } \\
\hline $\begin{array}{l}\text { Duration of attack prior } \\
\text { to ED presentation, } \mathrm{h}\end{array}$ & $71.7(32.6)$ & $15.5(1.3)$ & 0.01 & 56.2 (18.1 to 94.2$)$ \\
\hline Respiratory rate, breaths/min & $20.5(3.1)$ & $21.4(2.0)$ & 0.5 & $-0.9(-4.4$ to 2.6$)$ \\
\hline Heart rate, beats $/ \mathrm{min}$ & $92.3(3.9)$ & $102.5(1.3)$ & 0.005 & $-10.2(-14.4$ to -5.9$)$ \\
\hline $\mathrm{FEV}_{1}, \%$ of predicted & $34.8(11.1)$ & $23.0(1.2)$ & 0.2 & $11.8(-0.2$ to 23.8$)$ \\
\hline $\mathrm{SpO}_{2}, \%$ & $96.4(1.5)$ & $93.2(2.6)$ & 0.03 & $3.2(1.1$ to 5.3$)$ \\
\hline $\mathrm{pH}$ & $7.4(0.0)$ & $7.3(0.0)$ & 0.08 & $0.0(-0.0$ to 0.0$)$ \\
\hline $\mathrm{pO}_{2}, \mathrm{~mm} \mathrm{Hg}$ & $80.8(8.6)$ & $61.6(8.9)$ & 0.009 & 19.2 (8.7 to 29.6 ) \\
\hline $\mathrm{pCO}_{2}, \mathrm{~mm} \mathrm{Hg}$ & $34.8(2.9)$ & $39.8(1.0)$ & 0.01 & $-5.0(-8.2$ to -1.7$)$ \\
\hline $\mathrm{HCO}_{3}, \mathrm{mmol} / \mathrm{l}$ & $22.3(1.4)$ & $23.3(0.5)$ & 0.2 & $-1.0(-2.5$ to 0.5$)$ \\
\hline $\mathrm{Na}, \mathrm{mmol} / \mathrm{l}$ & $138.9(2.7)$ & $137.2(0.5)$ & 0.2 & $1.7(-1.2$ to 4.6$)$ \\
\hline $\mathrm{K}, \mathrm{mmol} / \mathrm{l}$ & $3.9(0.2)$ & $3.4(0.2)$ & 0.005 & $0.4(0.3$ to 0.6$)$ \\
\hline $\mathrm{Cl}, \mathrm{mmol} / \mathrm{l}$ & $102.0(3.3)$ & $100.5(1.0)$ & 0.3 & $1.5(-2.0$ to 5.0$)$ \\
\hline $\begin{array}{l}\text { Lactate, } \mathrm{mmol} / \mathrm{I} \\
\text { Final (120 } \mathrm{min})\end{array}$ & $1.1(0.5)$ & $1.3(0.2)$ & 0.4 & $-0.2(-0.7$ to 0.3$)$ \\
\hline Respiratory rate, breaths/min & $20.6(3.2)$ & $21.2(2.3)$ & 0.6 & $-0.6(-4.2$ to 3.0$)$ \\
\hline Heart rate, beats $/ \mathrm{min}$ & $99.0(8.7)$ & $109.0(2.1)$ & 0.04 & $-10.0(-19.4$ to -0.5$)$ \\
\hline $\mathrm{FEV}_{1}, \%$ of predicted & $70.9(23.0)$ & $73.0(22.6)$ & 0.7 & $-2.1(-29.6$ to 25.4$)$ \\
\hline $\mathrm{SpO}_{2}, \%$ & $97.2(1.5)$ & $98.0(1.4)$ & 0.3 & $-0.8(-2.5$ to 0.9$)$ \\
\hline $\mathrm{pH}$ & $7.4(0.0)$ & $7.3(0.0)$ & 0.2 & $0.0(-0.0$ to 0.0$)$ \\
\hline $\mathrm{pO}_{2}, \mathrm{~mm} \mathrm{Hg}$ & $82.8(10.2)$ & $82.3(10.9)$ & 0.6 & $0.5(-11.9$ to 12.9$)$ \\
\hline $\mathrm{pCO}_{2}, \mathrm{~mm} \mathrm{Hg}$ & $37.0(3.5)$ & $38.7(0.8)$ & 0.2 & $-1.7(-5.5$ to 2.1$)$ \\
\hline $\mathrm{HCO}_{3}, \mathrm{mmol} / \mathrm{l}$ & $22.6(0.9)$ & $21.9(1.2)$ & 0.2 & $0.7(-0.4$ to 1.8$)$ \\
\hline $\mathrm{Na}, \mathrm{mmol} / \mathrm{l}$ & $142.9(7.1)$ & $140.0(1.4)$ & 0.2 & $2.9(-5.6$ to 11.4$)$ \\
\hline $\mathrm{K}, \mathrm{mmol} / \mathrm{l}$ & $3.8(0.5)$ & $3.2(0.1)$ & 0.01 & $0.5(0.0$ to 1.0$)$ \\
\hline $\mathrm{Cl}, \mathrm{mmol} / \mathrm{l}$ & $105.2(7.6)$ & $102.2(0.9)$ & 0.2 & $3.0(-5.2$ to 11.2$)$ \\
\hline Lactate, $\mathrm{mmol} / \mathrm{l}$ & $2.0(0.7)$ & $6.6(1.5)$ & 0.003 & $-4.6(-5.7$ to -3.5$)$ \\
\hline
\end{tabular}


gluconeogenesis, and lypolysis. ${ }^{20}$ In particular, epinephrine (adrenaline) has been associated with increases in plasma lactate concentrations in normal volunteers ${ }^{22}$ and after cardiac surgery. ${ }^{23-25}$ Recently, several case reports have been published that linked lactic acidosis to inhaled $\beta_{2}$ agonist therapy in patients with acute asthma in absence of hypoxia or shock. ${ }^{6}{ }^{11}$

The findings of our study are in accordance with previous reports. We found that hyperlactataemia can develop during the first hours of treatment even in the absence of severe bronchial obstruction. In our group, $50 \%$ patients showed a rapid ( 2 hours) increase in lactate levels after the use of high doses of inhaled beta agonists, and four presented final very high levels $(\geqslant 4 \mathrm{mmol} / \mathrm{l})$. However, patients did not become acidotic from their lactate elevations, and $\mathrm{pCO}_{2}$ measurements also showed that these patients did not have respiratory alkalosis as compensation for acidosis. Our patients presented no evidence of liver or renal dysfunction. In addition, they had normal mean arterial pressures, and experienced no clinical or laboratory signs of hypoperfusion. The pretreatment degree of hypoxia was also not severe, and it showed an improvement after treatment. At the same time, bronchial obstruction improved, suggesting that lactate overproduction was not due to overworked respiratory muscles. Furthermore, the patients received no medication known to elevated lactate level, with the exception of the $\beta_{2}$ agonists. Thus, we believe that the increase in lactate level was mainly due to the large doses of inhaled $\beta_{2}$ agonists administered during ED treatment. Final lactate concentration was significantly correlated with pretreatment heart rate and inversely correlated with baseline serum potassium. Thus, patients with very high final lactate levels ( $\geqslant 4 \mathrm{mmol} / \mathrm{l}$ ) showed signs of exogenous adrenergic stimulation (tachycardia and hypokalaemia) pre-treatment, compared with patients with levels $<4 \mathrm{mmol} / \mathrm{l}$. Additionally, at presentation, patients with very high lactate levels were characterised by a rapid deterioration ( $<3$ hours), together with a more severe attack (lower $\mathrm{SpO}_{2}$ and $\mathrm{pO}_{2}$, higher $\mathrm{pCO}_{2}$, and a trend to a lower $\mathrm{FEV}_{1}$ ). Our findings suggest that the presence of a previous endogenous hyperadrenergic state (marked respiratory distress or anxiety related with more severe acute asthma) should predispose to the development of elevated lactate concentrations after ED treatment with large doses of inhaled beta agonists. In contrast, the possibility that large doses of exogenous beta agonists (received before ED treatment) encourage development of high lactate concentrations after ED treatment seems unlikely because this subgroup of patients had a rapid deterioration. Finally, lactate increase was associated with an improvement of respiratory function. Patients with final high lactate levels exhibited the characteristic rapid and complete response of acute asthmatics with rapid deterioration. ${ }^{26}$ Therefore, elevated post-treatment lactate did not affect the effectiveness of bronchodilator therapy and had no clinical consequences in these patients. Although hyperlactataemia was not high enough to cause acidosis, this finding is in agreement with previous reports that demonstrated that elevated lactate is not a marker of cellular hypoxia and has no negative indication in acute asthma. ${ }^{67}$

In summary, in this prospective and descriptive trial in an ED department, we have confirmed previous observations that high lactate concentrations can develop during the first hours of inhaled beta agonist treatment. This study suggests that elevated lactate levels may be more frequent than presently estimated. We suggest that this increase was mostly due to large doses of inhaled $\beta_{2}$ agonists administered during ED treatment. The presence of a previous hyperadrenergic state related with more severe disease should predispose to the development of this condition. Finally, there was a significant improvement associated with elevated lactate levels.

However, these conclusions are limited by several factors. (a) A primary weakness is lack of a control group not treated with beta agonists that could demonstrate that lactate increase is a treatment related effect. (b) It would, of course, be unethical to withhold albuterol, thus because each patient received the same amount of albuterol, the study did not consider the relationship between albuterol doses and lactate levels. However, an increase in albuterol dose from $400 \mu$ g every 10 minutes produces a slightly better therapeutic response but with greater side effects. ${ }^{21}$ (c) Although all patients received beta agonists prior to ED presentation, there was no quantification of the doses received to assist in measuring any previous hyperadrenergic state.

\section{Authors' affiliations}

G J Rodrigo, Departamento de Emergencia, Hospital Central de las Fuerzas Armadas, Montevideo, Uruguay

C Rodrigo, Unidad de Cuidado Intensivo, Asociación Española 19 de Socorros Mutuos, Montevideo, Uruguay

Competing interests: none declared

\section{REFERENCES}

1 Roncoroni AJ, Adrogué HJA, de Obrutsky CW, et al. Metabolic acidosis in status asthmaticus. Respiration 1976;33:85-94.

2 Appel D, Rubenstein R, Schrager K, et al. Lactic acidosis in severe asthma. Am J Med 1983;75:580-4.

3 Alberts WM, Williams JH, Ramsdell JW. Metabolic acidosis as a presenting feature in acute asthma. Ann Allergy 1986;57:107-9.

4 Mountain RD, Heffner JP, Brackett NC, et al. Acid-base disturbances in acute asthma. Chest 1990;98:651-5.

5 James JH, Luchette FA, McCarrer FD, et al. Lactate is an unreliable indicator of tissue hypoxia in injury or sepsis. Lancet 1999;354:505-8.

6 Maury $\mathrm{E}$, loos V, Lepecq B, et al. A paradoxical effect of bronchodilators. Chest 1997; 111:1766-7.

7 Cotton DB, Strassner HT, Lipson LG, et al. The effects of terbutaline on acid base, serum electrolytes, and glucose homeostasis during the management of preterm labor. J Obstet Gynecol 1981;141:617-24.

8 St Jean O, Rohan Chabot P, Thaler F, et al. Hyperlactatemia during treatment of acute bronchospasm with salbutamol. Presse Med 1987; 16:965-6.

9 Manthous CA. Lactic acidosis in status asthmaticus. Three cases and review of the literature. Chest 2001;119:1599-602.

10 Prakash S, Metha S. Lactic acidosis in asthma: report of two cases and review of literature. Can Respir J 2002;9:203-8.

11 Stratakos G, Kolomenidis J, Routsi C, et al. Transient lactic acidosis as a side effect of inhaled salbutamol. Chest 2002;122:385-6.

12 Yousef E, McGeady SJ. Lactic acidosis and status asthmaticus: how common in pediatrics? Ann Allergy Asthma Immunol 2002;89:585-8.

13 Stiles GL, Caron MG, Lefkowitz RJ. $\beta$-adrenergic receptors: biochemical mechanisms of physiological regulation. Physiol Rev 1984;64:661-743.

14 NHLBI/WHO. Workshop report: global strategy for asthma management and prevention, NIH Publication 02-3659, 2002.www.ginasthma.com.

15 American Thoracic Society. Standardization of spirometry - 1994 update. Am J Resp Crit Care Med 1995; 152:1107-36.

16 McFadden ER, Kiser R, deGroot WJ. Acute bronchial asthma: relations between clinical and physiologic manifestations. N Engl J Med 1973;288:221-5

17 Altman DG, Machin D, Bryant TN, et al. Statistics with confidence. Bristol, UK: British Medical Journal Books, 2000.

18 Vincent JL, Dufaye P, Berre J. Serial lactate determinations during circulatory shock. Crit Care Med 1983; 1 1:449-51.

19 Vincent JL. Lactate levels in critically ill patients. Acta Anaesthesiol Scand 1995;107(suppl):261-6

20 Haffner CA, Kendall MJ. Metabolic effects of $\beta_{2}$-agonists. J Clin Pharm Ther 1992;17:155-64.

21 Rodrigo G, Rodrigo C. Metered dose inhaler salbutamol treatment of asthma in the ED: Comparison of two doses with plasma levels. Am J Emerg Med 1996; 14:144-50.

22 Ensinger II, Lindner KII, Kirks B, et al. Adrenaline: relationship between infusion rate, plasma concentration, metabolic and hemodynamic effects in volunteers. Eur J Anaesthesiol 1992:9:435-46.

23 Maillet JM, Besnerais PL, Cantoni M, et al. Frequency, risk factors, and outcome of hyperlatatemia after cardiac surgery. Chest 2003; 123:1361-6. 
24 Raper RF, Cameron G, Walker D, et al. Type B lactic acidosis following cardiopulmonary bypass. Crit Care Med 1997;25:45-51.

25 Totaro R, Raper RF. Epinephrine induced lactic acidosis following cardiopulmonary bypass. Crit Care Med 1997;25:1693-9.
26 Rodrigo GJ, Rodrigo C. Rapid-onset asthma attack. A prospective cohort study about characteristics and response to emergency department treatment. Chest 2000; 118:1547-52.

27 Lissac J. Acidosis in severe acute asthma. Presse Med 1996;25:1411-14.

\section{Clinical Evidence-Call for contributors}

Clinical Evidence is a regularly updated evidence-based journal available worldwide both as a paper version and on the internet. Clinical Evidence needs to recruit a number of new contributors. Contributors are healthcare professionals or epidemiologists with experience in evidence-based medicine and the ability to write in a concise and structured way.

Areas for which we are currently seeking authors:

- Child health: nocturnal enuresis

- Eye disorders: bacterial conjunctivitis

- Male health: prostate cancer (metastatic)

- Women's health: pre-menstrual syndrome; pyelonephritis in non-pregnant women However, we are always looking for others, so do not let this list discourage you.

Being a contributor involves:

- Selecting from a validated, screened search (performed by in-house Information Specialists) epidemiologically sound studies for inclusion.

- Documenting your decisions about which studies to include on an inclusion and exclusion form, which we keep on file.

- Writing the text to a highly structured template (about 1500-3000 words), using evidence from the final studies chosen, within 8-10 weeks of receiving the literature search.

- Working with Clinical Evidence editors to ensure that the final text meets epidemiological and style standards.

- Updating the text every six months using any new, sound evidence that becomes available. The Clinical Evidence in-house team will conduct the searches for contributors; your task is simply to filter out high quality studies and incorporate them in the existing text.

- To expand the topic to include a new question about once every 12-18 months.

If you would like to become a contributor for Clinical Evidence or require more information about what this involves please send your contact details and a copy of your CV, clearly stating the clinical area you are interested in, to Klara Brunnhuber (kbrunnhuber@ bmigroup.com).

\section{Call for peer reviewers}

Clinical Evidence also needs to recruit a number of new peer reviewers specifically with an interest in the clinical areas stated above, and also others related to general practice. Peer reviewers are healthcare professionals or epidemiologists with experience in evidence-based medicine. As a peer reviewer you would be asked for your views on the clinical relevance, validity, and accessibility of specific topics within the journal, and their usefulness to the intended audience (international generalists and healthcare professionals, possibly with limited statistical knowledge). Topics are usually 1500-3000 words in length and we would ask you to review between 2-5 topics per year. The peer review process takes place throughout the year, and our turnaround time for each review is ideally 10-14 days.

If you are interested in becoming a peer reviewer for Clinical Evidence, please complete the peer review questionnaire at www.clinicalevidence.com or contact Klara Brunnhuber (kbrunnhuber@bmigroup.com). 